\title{
Alendronate Treatment for Infants with Osteogenesis Imperfecta: Demonstration of Efficacy in a Mouse Model
}

\author{
EDITH A. MCCARTHY, CATHLEEN L. RAGGIO, MICHAEL D. HOSSACK, \\ ELIZABETH A. MILLER, SARGAM JAIN, ADELE L. BOSKEY, AND NANCY P. CAMACHO \\ Research Division, The Hospital for Special Surgery, New York, New York, U.S.A. [C.L.R., M.D.H., \\ E.A.Mi. S.J., A.L.B., N.P.C.]; Perinatology Division, The New York Presbyterian Hospital-Cornell \\ University, New York, New York, U.S.A. [E.A.Mc.]
}

\begin{abstract}
ABST
Recent non-placebo-controlled studies of the bisphosphonate
pamidronate have shown it to be effective in reducing fractures
and improving bone density in infants and children with osteo-
genesis imperfecta (OI). To evaluate the effects of bisphospho-
nate treatment in a controlled study, the oim/oim mouse model of
OI was studied. Nursing infant mouse pups $(\sim 2$ wk old) with
moderate to severe OI (oim/oim mouse) and age- and back-
ground-matched control mice $(+/+)$ were treated either with the
third-generation bisphosphonate alendronate $($ ALN), or with sa-
line. Fracture risk, bone quality, and growth were evaluated over
a 12 -wk treatment period. ALN at a dose of 0.03 mg/kg/d or
saline was administered via s.c. injection to infant oim/oim and
wild-type ( $+/+)$ mice from 2 to 14 wk of age $(n=20$ per
subgroup). The average number of fractures sustained by the
ALN-treated oim/oim mice was reduced significantly compared
with the untreated oim/oim mice $(0.7 \pm 0.7$ fractures/mouse
versus $2.0 \pm 0.2$ fractures/mouse). Bone density increased sig-
nificantly in the femur and the spine with treatment $(2.0 \pm 0.5$
versus $1.2 \pm 0.5$ in femur and $2.1 \pm 0.5$ versus $1.6 \pm 0.5$ in
spine). Histologic evaluation revealed the percentage of metaph-
yseal tibial bone increased significantly with treatment in both
$+/+$ and oim/oim mice. Mechanical testing revealed an increase
\end{abstract}
OI, also known as "brittle bone disease," occurs in about 1 in 20,000 births (1). The real incidence is probably higher because a significant number of children are not diagnosed at birth due to mild expression of the disease (2). OI is predominately a collagen defect, caused by heterogeneous genetic mutations that result in an array of clinical manifestations, ranging from blue sclerae and dentinogenesis imperfecta to

Received June 25, 2001; accepted June 26, 2002.

Correspondence: Edith A. McCarthy, M.D., Neonatology Division, NYU Medical Center, 530 First Avenue, Suite 7A, New York, NY, 10016, U.S.A; e-mail: EM9119@aol.com

Supported by a grant from the Osteogenesis Imperfecta Foundation (The Michael Geisman Fellowship Award to E.A.M.) and by National Institutes of Health Grant numbers DE11803 (N.P.C.) and AR46121.

DOI: 10.1203/01.PDR.0000032068.76811.0D in structural stiffness for both treated $+/+$ and oim/oim mice compared with untreated animals. None of the material properties examined were significantly altered with treatment, nor was spinal curvature affected. Weight gain and long bone growth were comparable in the treated and untreated oim/oim mice. In wild-type mice, femur lengths were significantly shorter in the treated mice compared with untreated counterparts. This animal study demonstrates that treatment of OI in mice as early as $2 \mathrm{wk}$ of age with ALN appears to be effective in reducing fractures and increasing bone properties. Based on the data from this study, ALN therapy in infants with OI should prove to be effective.

(Pediatr Res 52: 660-670, 2002)

OI, osteogenesis imperfecta

\section{Abbreviations}

oim/oim, mice homozygous for spontaneous mutation causing the skeletal defects of OI

$+/+$, wild-type mice

AP, anteroposterior

ML, mediolateral

BMD, bone mineral density

ALN, alendronate extremely short stature and progressive limb/spine deformities secondary to multiple fractures. Surgical treatment of the extremities and spine are often indicated to stabilize the long bones and optimize functional ability and walking capacity. According to the Sillence classification (3) there are four forms of OI, although recent data has added additional variants (4). Type II OI is lethal in the perinatal period, due to a restrictive pulmonary hypoplasia secondary to abnormal development of the rib cage in utero. Type III OI is the most severe form in children surviving the neonatal period, and life expectancy in these patients is reduced (5).

Clearly, despite marked clinical variability, OI is a devastating disease that often presents at birth and needs to be treated as early as possible to improve quality of life and outcome for 
these children. Before the recent use of bisphosphonates in the treatment of OI, medical management of OI had been largely ineffective in altering the course of the disease. Pharmaceutical interventions with sodium fluoride, calcitonin (6), and GH (7) have been tried, but the most promising drugs to date appear to be the bisphosphonates. Bisphosphonates are stable analogs of inorganic pyrophosphate, which have been developed over the past three decades as potent inhibitors of osteoclast-mediated bone resorption and effective agents for the management of osteoporosis and other bone diseases. Bisphosphonates may inhibit osteoclast-mediated bone resorption by several routes, including decreased osteoclast progenitor development, decreased osteoclast recruitment, and promotion of apoptosis of mature osteoclasts leading to decreased bone remodeling (8). According to Rogers et al. (9), bisphosphonates most likely act on mature osteoclasts by perturbing cellular metabolism and inducing osteoclast apoptosis. Other studies raise the possibility that increased survival of osteoblasts and osteocytes through inhibition of apoptosis may contribute to the efficacy of bisphosphonates in the management of disease states due to loss of bone, such as glucocorticoid-induced osteoporosis (8).

Several investigators have reported beneficial effects of bisphosphonate treatment in children with severe forms of OI. Devogelaer et al. in 1987 (10) and Huaux and Lokeitek in 1988 (11) were the first to report decreased fracture rate and pain in children with severe OI treated with bisphosphonates. Lansmeer-Beker et al. (12) in 1997 reported a decrease in fracture number, an increase in calcification of long bones, and amelioration of vertebral shape in three boys with severe OI type III treated for 5-7 y with the bisphosphonate olpadronate. Bembi et al. (13) first reported an increase in BMD in children with OI treated with pamidronate for a period ranging from 22 to 29 mo. Astrom and Soderhall (14) reported a major improvement in well-being, pain, and activities of daily life using pamidronate over a 2-5 y treatment period. Of note, the effect on the younger patients in this study was more pronounced than that observed in the older patients, perhaps owing to a higher rate of bone turnover at a younger age. The most recent published data supporting the use of bisphosphonates in infants and children with OI is the work of Glorieux et al. (15), and Plotkin et al. (16), who have treated children ranging in age from 3 to $16 \mathrm{y}$ and severely affected infants ranging in age from 2.3 to 20.7 mo with the bisphosphonate pamidronate. Here, treatment was reported to be safe, to increase BMD, and to decrease fracture rate. Unfortunately, these recent studies were not placebo-controlled, the ultimate test of drug efficacy, and histologic evaluation of bone quality was not possible.

Because fractures begin in infancy in OI, or even in utero or perinatally, it is logical to speculate that treatment with bisphosphonates would be most beneficial if initiated early in life. There are concerns, however, over safety issues involved in treating an infant whose bones are rapidly growing and remodeling with a drug that inhibits bone resorption. In animal studies, high doses of bisphosphonates given to growing rats have been found to decrease growth (17) and femur length (18). Similar studies in an animal model of OI are needed to evaluate the effect of treatment on growth and to look histologically at the effects of bisphosphonates on bone quality.
Such studies should confirm the safety and efficacy of bisphosphonates in reducing fracture risk and increasing bone quality in infant mice with OI.

The animal model used in the current study is the oim mouse, a naturally occurring established animal model of OI (19). Mice homozygous for the oim mutation (oim/oim) are deficient in pro $\alpha 2(\mathrm{I})$ collagen. This collagen defect produces phenotypic and biochemical features similar to moderate to severe forms of human OI, such as limb deformities, osteopenia, small body size, and skeletal fractures. Thus, the oim/oim mouse provides a model of human OI that can be used to study the effects of experimental therapies, such as bisphosphonates, thereby providing information critical to design of a long-term therapeutic protocol for infants with OI. The current study investigates the efficacy of the bisphosphonate ALN in infant oim/oim mice over a 12-wk treatment period.

This study was approved by the Institutional Animal Care and Use Committee at The Hospital for Special Surgery, New York, NY, U.S.A.

\section{METHODS}

\section{Subjects}

Breeder wild-type mice $(+/+)$ (strain: B6C3Fe-a/a $+/+$ ) and mice homozygous for the spontaneous mutation that causes the skeletal defects of OI (oim/oim) (strain: B6C3Fe$\mathrm{a} / \mathrm{a} /$ Cola $2^{\text {oim/oim }}$ ) were initially obtained from Jackson Laboratory (Bar Harbor, ME, U.S.A.). Breeding pairs were set up to yield a desired number of 80 mouse pups to be used in the study, 40 affected oim/oim mice and $40+/+$ control mice. Parents and offspring were maintained at $75^{\circ} \mathrm{F}$ on a diet of tap water and standard laboratory rodent chow during the study. Powdered food was used for the mice affected with OI, inasmuch as their teeth can be also affected in OI by dentinogenesis imperfecta.

\section{Protocol}

At 2 wk of age, $+/+$ and oim/oim offspring were each randomized into two subgroups (20 mice per group) to receive weekly s.c. injections of either ALN (Merck, Whitehouse Station, NJ, U.S.A.) at a dose of $0.03 \mathrm{mg} / \mathrm{kg} / \mathrm{d}$ or saline in an equal volume of $0.1 \mathrm{~mL} / 10 \mathrm{~g}$ body weight. The dosage was previously determined in a pilot study (20). Mice were weighed weekly for adjustment of dosage and tracking of weight gain. Pups were weaned from their mothers at $4 \mathrm{wk}$ of age, and male and female pups separated. The infant pups were treated from 2 to $14 \mathrm{wk}$ of age, at which time the mice were killed via tubocurarine injection under ketamine sedation. This method of sacrifice was chosen to minimize artifacts of rigor mortis on spinal curvature measurement. A baseline group of oim/oim mice were also examined at $2 \mathrm{wk}$ of age to determine fracture number at this age ( $n=7$ per genotype).

\section{Measurements}

Fracture count. After sacrifice, high-resolution whole-body AP and lateral radiographs were taken via Faxitron (Hewlett Packard, Palo Alto, CA, U.S.A.). Fractures were counted on 
illuminated and magnified radiographs by examining the following bones: bilateral femora, tibiae, humeri, and tails. Fracture count was performed by a blinded observer: an orthopedic surgeon with significant experience in fracture determination (C.L.R.).

Spinal curvature. Radiographs were digitized and SigmaScan software (SPSS Science, Chicago, IL, U.S.A.) used to measure spinal curvature (cervical lordosis and thoracic kyphosis) using Cobb's angle measurement (21).

Bone geometry. Whole spines were carefully dissected out at sacrifice, cleaned of soft tissue, and radiographed in the AP plane. Measurements of vertebral height and width were made at L2 in each dissected spine, using the iliac crest as an anatomical point of reference. Individual femora were also dissected at sacrifice, cleaned of soft tissue, and radiographed in the AP and ML planes. Femur length, endosteal $\left(d_{\mathrm{e}}\right)$ and periosteal $\left(d_{\mathrm{p}}\right)$ diameters were measured in the AP and ML planes from digitized radiographs. Femur length was determined as the distance from the tip of the femoral head to the base of the condyles. The midpoint of the femur was used to measure $d_{\mathrm{e}}$ and $d_{\mathrm{p}}$. Cortical thickness was calculated as the difference between endosteal and periosteal diameter. Based on the diameteral measurements in the AP and ML planes, the femoral cross-section was estimated to be elliptical. The moment of inertia, $I$, a measure of the distribution of material around a given axis, was calculated as:

$$
I_{\text {ellipse }}=\frac{\pi}{4}\left[\left(\frac{A P d_{\mathrm{p}}}{2}\right)\left(\frac{M L d_{\mathrm{p}}}{2}\right)^{3}-\left(\frac{A P d_{\mathrm{e}}}{2}\right)\left(\frac{M L d_{\mathrm{e}}}{2}\right)^{3}\right]
$$

where $d_{\mathrm{p}}$ in the AP plane corresponds to the major diameter of the ellipse, and $d_{\mathrm{p}}$ in the ML plane corresponds to the minor diameter (22).

Bone biomechanics. Mechanical testing of femurs via threepoint bend testing was performed to evaluate differences in structural and material bone properties. Testing was performed at room temperature, using a closed-loop servo-hydraulic test machine (MTS Systems Corporation, Eden Prairie, MN, U.S.A.) with Instron electronic controls (Instron Corporation, Canton, MA, U.S.A.). The bones were placed with their anterior aspect facing down on two supports equidistant from their ends and separated by a constant distance [length $(L)=8 \mathrm{~mm}$ for the 14-wk old mice) and centrally loaded from the posterior aspect of the bone at a constantly increasing rate $(0.5 \mathrm{~N} / \mathrm{s})$ until fracture. Stiffness was determined by taking the slope of the elastic region of the load-displacement curve. Load and displacement data were then normalized to the moment of inertia, $I$, to obtain material properties (22).

The stress was calculated as:

$$
\sigma=\frac{M c}{I_{\text {ellipse }}}
$$

where $M$ is the maximum load, $c$ is the distance from the neutral axis to the point of loading, equal to one half the AP periosteal diameter, and $I_{\text {ellipse }}$ is the moment of inertia (22). Stress-strain curves were calculated, and Young's modulus determined by taking the slope of the elastic region of the curve as a measure of the intrinsic stiffness of the material. Yield strain (point of maximum elastic deformation) divided by ultimate strain * 100 was also calculated and termed "brittleness."

Bone density. Femurs dissected at sacrifice were radiographed in the AP plane with an aluminum alloy density step standard. Radiographs were digitized and density measurements taken using Sigma Chemical scan software (Sigma Chemical, St. Louis, MO, U.S.A.). Each individual image was calibrated using the steps as the density standards with intensity units ranging from 1 to 3 . Femoral cortical density was determined by averaging density measurements of two 1-mmlong rectangular areas along the mid-shaft of the cortex. For metaphyseal density, measurements were taken of a 1-mm area located $2 \mathrm{~mm}$ proximal to the femoral condyles. Vertebral density measurements were also made using SigmaScan software to analyze dissected lumbar spines via digitized AP radiographs. For consistency, measurements were made on the same vertebra, L2, using the iliac crest as a point of reference. Two spine density measurements were taken: metaphyseal and trabecular. The metaphyseal spine density was measured using a $1-\mathrm{mm}$ by $1-\mathrm{mm}$ area immediately adjacent to the endplate between the cortex and the spinous process. The trabecular spine density was measured using a $1-\mathrm{mm}$ by $1-\mathrm{mm}$ area located $0.7 \mathrm{~mm}$ away from the endplate and $1.5 \mathrm{~mm}$ medial to the cortex (Fig. 1).

Bone histology. For histologic evaluation, dissected tibiae were fixed in glutaraldehyde, decalcified in 10\% EDTA, embedded in JB4 resin, and sectioned longitudinally at $3 \mu \mathrm{m}$ thickness. They were then stained with Safranin O, a stain specific for cartilage proteoglycans (23), and counter-stained with Fast Green. This method was used to differentiate bone, which stains light green, from calcified cartilage, which stains red. Growth plate heights were measured from these sections using Metamorph software (Universal Imaging Corp., West Chester, PA, U.S.A.). Tibial diameter was determined across the growth plate, and the growth plate height measured at three points near mid-diameter. These data were then averaged to obtain one value per section. A grid-counting method was used to calculate the percentage of bone and calcified cartilage present in the primary spongiosa in a $0.5 \times 0.5 \mathrm{~mm}^{2}$ region directly under the epiphyseal plate. Two separate sections of each tissue were analyzed to calculate the average percentage of bone under the growth plate. Dissected spines were also evaluated histologically. After fixation in glutaraldehyde and decalcification in 10\% EDTA, spines were embedded in paraffin, stained with hematoxylin and eosin and sectioned at 3 $\mu \mathrm{m}$ thickness for qualitative microscopic examination.

Data analysis. Statistical analyses were performed on SigmaStat software (SPSS Science). Univariate statistics were collected on all variables, including means, medians, ranges, and SD. Parametric data were analyzed by two-factor ANOVA to test for the simultaneous effects of genotype and ALN treatment on the outcome variables. Three null hypotheses were examined: 1) there is no effect of genotype, 2) there is no effect of ALN treatment, and 3) the potential effect of ALN treatment is independent of genotype (the interaction term). If significant differences were found for any factors, multiple comparisons were performed using Student-Newman-Keuls to 


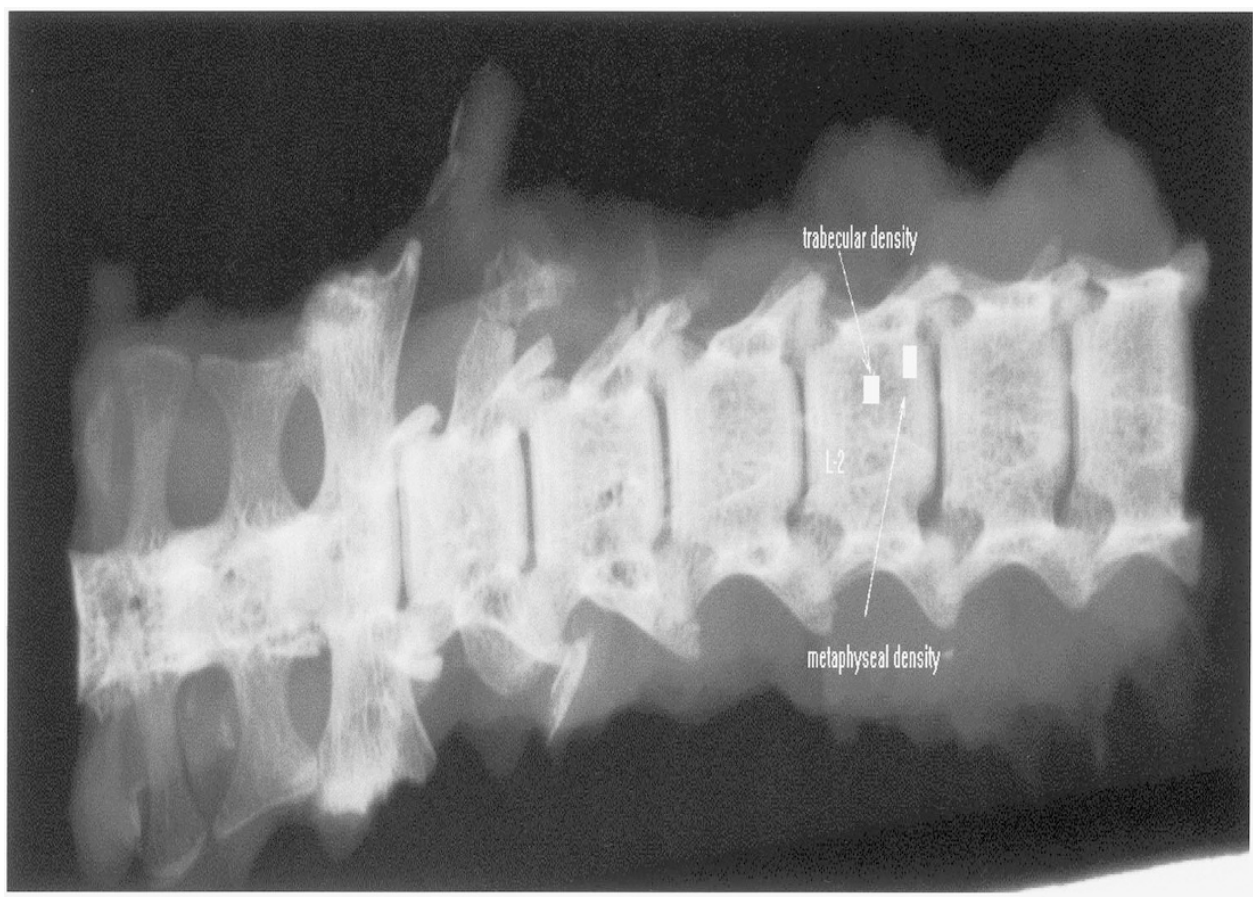

Figure 1. Vertebral density measurements. Faxitron of dissected lumbosacral spine. Metaphyseal spine density at L2 was measured using a 1-mm by 1-mm area immediately adjacent to the endplate between the cortex and the spinous process. The trabecular spine density at L2 was measured using a 1-mm by 1 -mm area located $0.7 \mathrm{~mm}$ away from the endplate and $1.5 \mathrm{~mm}$ medial to the cortex.

test for differences with ALN treatment within either oim/oim mice or wild-type $(+/+)$ mice $(24)$. Values were considered significantly different at $p<0.05$. Although the oim gene is not sex-linked, all measurements were analyzed separately for males and females. Because significant differences were not found based on gender, the data for males and females were grouped together. For fracture counting, a nonparametric measurement, the Mann-Whitney rank sum test, was used with differences considered significant at $p<0.05$.

\section{RESULTS}

Growth. At baseline 2 wk of age, $(+/+)$ mice had significantly larger average weights than the oim/oim mice. (Table 4) Throughout the 12 wk of evaluation, ALN treatment did not appear to have an adverse effect on weight gain in either the $+/+$ or oim/oim mice. Growth curves in treated versus nontreated groups were comparable for both wild-type and OIaffected mice (Fig. 2).

Similarly, at $2 \mathrm{wk}$ baseline and at the end of the $12 \mathrm{wk}$ of study, $+/+$ mice had longer femur lengths than their oim/oim counterparts (Tables 1-4). ALN treatment did not appear to have an adverse effect on long bone growth with treatment in the oim/oim mice, as femur lengths after 12 wk of treatment were comparable to those of untreated oim/oim mice. However, femur lengths in the $+/+$ mice after $12 \mathrm{wk}$ of ALN treatment were significantly shorter than those of their untreated counterparts. This discrepancy in the effect of treatment on $+/+$ versus oim/oim mice was confirmed by the significance of the two-way ANOVA interaction factor, $p=0.025$.

Fracture number. The average number of fractures sustained by the ALN-treated oim/oim mice was significantly reduced to $0.7 \pm 0.7$ fractures/mouse compared with untreated oim/oim mice, who sustained $2.0 \pm 0.2$ fractures/mouse ( $p=$ $0.006)$. Whereas $86 \%(19 / 22)$ of the oim/oim control mice sustained fractures, only $58 \%(11 / 19)$ of the ALN-treated oim/oim mice sustained fractures. To account for fractures sustained before the treatment period, fracture incidence was also examined in 2-wk-old baseline mice, who had not been subjected to either handling or injections. The fracture incidence in baseline 2-wk-old oim/oim mice was identical to that of 14-wk-old oim/oim mice who had been treated with ALN from 2 to 14 wk of age, $0.7 \pm 0.8$ fractures/mouse.

Bone density. Density measurements were not obtained in baseline 2-wk old mice due to technical limitations of the density standard. However, at sacrifice at $14 \mathrm{wk}$ of age, the density of the cortical and metaphyseal femoral bone in $+/+$ mice treated with saline was greater than that seen in the same regions of oim/oim bone also treated with saline, emphasizing the difference in bone quality between the oim/oim mouse model and a wild-type mouse. Femoral density in the cortical region of bone did not change significantly with treatment in the oim/oim mice. However, density in the femoral metaphyseal region did increase with ALN treatment in oim/oim mice (Fig. 3). Vertebral density in both the metaphyseal and trabecular regions also increased significantly with treatment in oim/oim mice (Fig. 4). In fact, with treatment, both the vertebral density and femoral metaphyseal density of oim/oim mice increased to equal that of untreated wild-type mice (Figs. 3 and 4).

Spinal curvature. The spinal curves of untreated oim/oim mice were not significantly greater than those of untreated $+/+$ mice at $14 \mathrm{wk}$ of age. Furthermore, cervical lordosis and 


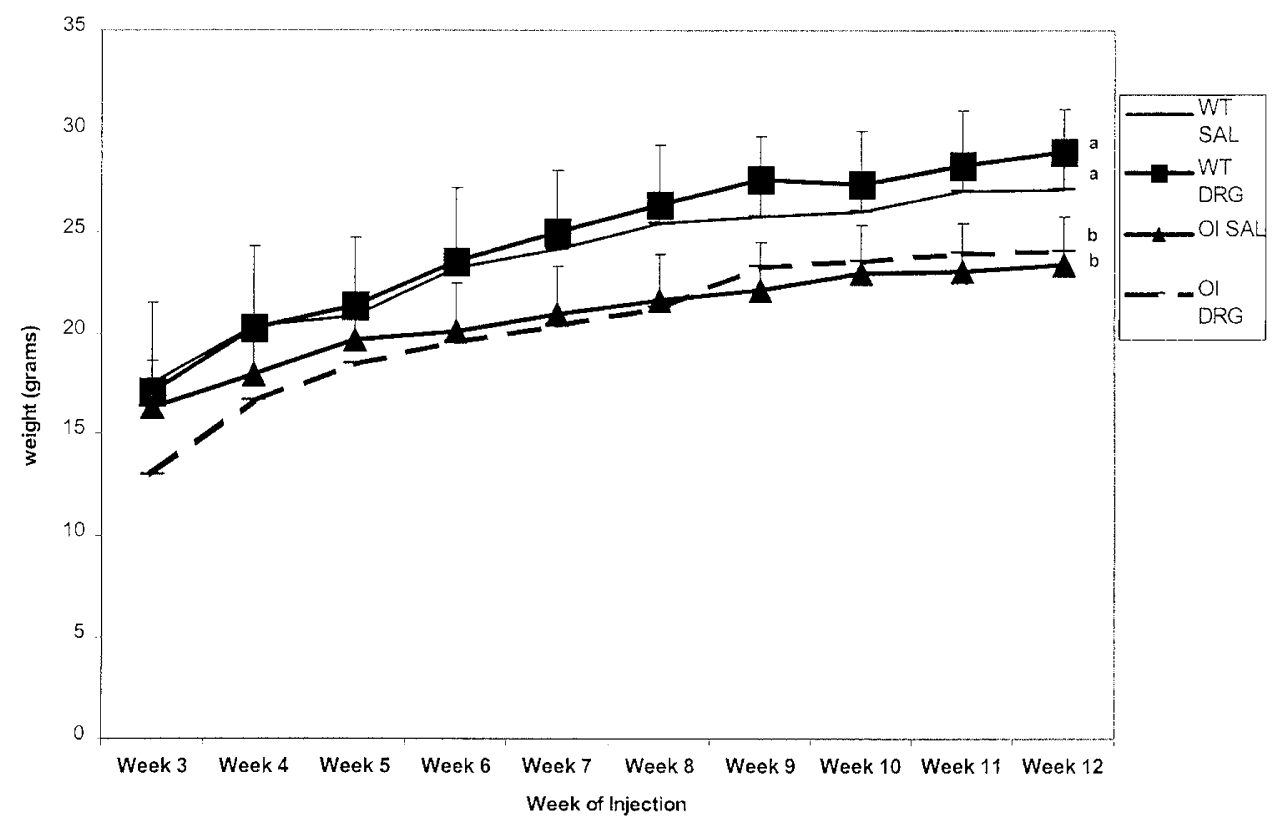

Figure 2. Growth curves plotted over the 12-wk course of the study. No significant difference was noted in weights at sacrifice between treated and untreated mice in either $+/+$ or oim/oim mice. $+/+$ mice were significantly larger than oim/oim mice in both treatment categories. Lines denoted by different letters are significantly different from each other $(p<0.05)$.

Table 1. Average femur length after 12 wk of treatment

\begin{tabular}{clcc}
\hline Genotype & Treatment & $\begin{array}{c}\text { Femur length } \\
(\mathrm{mm})^{*}\end{array}$ & No. of animals \\
\hline$+/+$ & Saline & $16.00 \pm 0.50$ & 22 \\
$+/+$ & Alendronate & $15.38 \pm 0.42^{* *}$ & 20 \\
oim/oim & Saline & $15.38 \pm 0.39^{* *}$ & 22 \\
oim/oim & Alendronate & $15.52 \pm 0.61$ & 19 \\
\hline
\end{tabular}

Baseline femur length at $2 \mathrm{wk}$ of age is smaller in oim/oim mice than wild-type mice.

* Results are expressed as the mean femur length $(\mathrm{mm}) \pm \mathrm{SD}$ in wild-type $(+/+)$ and oim/oim mice after $12 \mathrm{wk}$ of treatment with either saline or alendronate. Comparisons were made using the two-way ANOVA.

** Denotes significant difference vs untreated $+/+$ mice (Student-NewmanKeuls method, $p<0.05$ ).

thoracic kyphosis were not significantly altered with treatment in oim/oim mice.
Bone geometry. At baseline $2 \mathrm{wk}$ of age, there were no significant differences in bone geometry between wild-type and OIM mice (Table 4). After $12 \mathrm{wk}$ of treatment, again no significant differences were noted in bone geometry between mice treated with ALN versus those receiving only saline (Table 2). There was a tendency toward increasing femoral periosteal ML diameter in the $+/+$ mice with treatment $(p=$ 0.07).

Bone histology. ALN treatment increased the percentage of bone under the growth plate (primary spongiosa) significantly: from $23.89 \% \pm 9.81 \%$ to $30.35 \% \pm 5.58 \%$ in $+/+$ mice $(p<$ 0.01 ), and from $12.29 \% \pm 5.28 \%$ to $22.35 \% \pm 9.59 \%$ in oim/oim mice $(p<0.01)$ (Fig. 5). Tibial growth plate heights tended to be greater in untreated oim/oim mice at $14 \mathrm{wk}$ of age compared with age-matched untreated $+/+$ mice $(124.2 \mu \mathrm{m} \pm$ 11.3 versus $114.0 \mu \mathrm{m} \pm 16.9 ; p=0.07)$. With ALN treatment,

Table 2. Geometrical properties of bone after 12 wk of treatment (mean $+S D)$

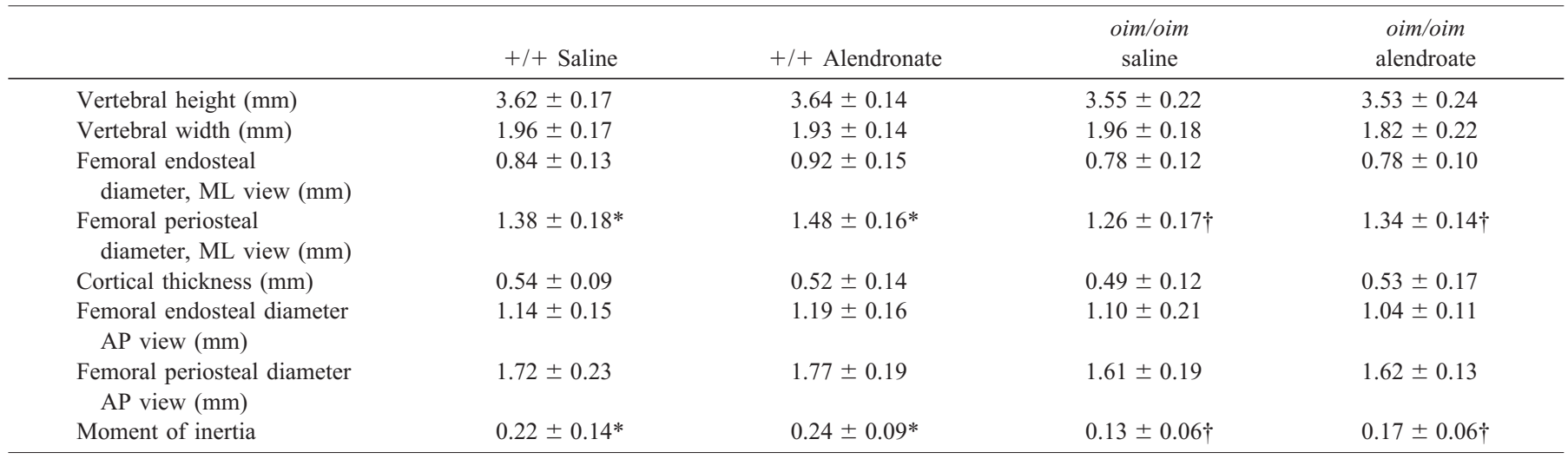

Results represent geometrical properties of wild-type $(+/+)$ and oim/oim bone after $12 \mathrm{wk}$ of treatment with either saline or alendronate. Note: at baseline and $2 \mathrm{wk}$ of age there are no differences in geometrical properties between wild-type and OI bones.

$*, \uparrow$ Values denoted by $\dagger$ are significantly different from values denoted by $*$ for said parameter $(p<0.05)$. 
Table 3. Biomechanical data: structural and material properties of femora after 12 wk of treatment

\begin{tabular}{|c|c|c|c|c|}
\hline & $+/+$ Saline & $\begin{array}{c}+/+ \\
\text { Alendronate }\end{array}$ & oim/oim Saline & $\begin{array}{c}\text { oim/oim } \\
\text { Alendronate }\end{array}$ \\
\hline No. & 20 & 19 & 21 & 16 \\
\hline Structural stiffness $(\mathrm{N} / \mathrm{mm})$ & $42.7 \pm 11.5 \dagger$ & $53.2 \pm 16.6^{* \dagger}$ & $30.3 \pm 6.8 \ddagger$ & $40.8 \pm 7.0 * \div$ \\
\hline Breaking strength (MPa) & $167.5 \pm 40.7 \dagger$ & $178.6 \pm 32.3 \dagger$ & $107.8 \pm 34.6 \$$ & $108.6 \pm 21.6 \ddagger$ \\
\hline Young's modulus (GPa) & $3071.2 \pm 999.5$ & $3302.6 \pm 964.1$ & $3398.1 \pm 1601.0$ & $3368.9 \pm 1023.1$ \\
\hline Brittleness ( $\%$ elasticity) & $73.8 \pm 20.0 \dagger$ & $81.2 \pm 16.9 \dagger$ & $97.71 \pm 5.2 \ddagger$ & $97.6 \pm 4.7 \ddagger$ \\
\hline
\end{tabular}

Values represent biomechanical data, expressed as mean $\pm \mathrm{SD}$, for wild-type $(+/+)$ and oim/oim mice after 12 wk of treatment with either saline or alendronate. ${ }^{*} p<0.05$ treated $v s$ control, same genotype.

$\dagger, \$$ Values denoted by $\ddagger$ are significantly different from values denoted by $\dagger$ for that specific parameter $(p<0.01)$.

the tibial growth plates in the oim/oim mice tended to be narrower than in untreated oim/oim mice (115.7 \pm 14.5 versus $124.2 \mu \mathrm{m} \pm 16.9 ; p=0.07)$, actually approaching the width of untreated $+/+$ growth plates $(114.0 \mu \mathrm{m} \pm 16.9)$ (Fig. 5). Qualitative analysis of the spine histology in the untreated oim/oim mice revealed two primary findings: 1) marked disorganization of the growth plate, and 2) decreased crossconnectivity between bone trabeculae, which also appeared thin (Fig. 6). With treatment, the spines in the oim/oim mice showed an increase in cross-connectivity and width of trabeculae as well as an increase in the amount of calcified cartilage under the growth plate. In general, the growth plates in ALNtreated oim/oim mice appeared more organized in alignment.

Bone biomechanics. Oim/oim femora are significantly more brittle (as measured by percentage elasticity) than $+/+$ bones both with and without treatment with bisphosphonate (Table 3 ), supporting the definition of OI as "brittle bone disease." Biomechanical testing of femora revealed an increase in the structural stiffness for oim/oim mice treated with ALN (Table 3). Failure load increased significantly with treatment only for $+/+$ mice. None of the material properties examined were significantly altered with treatment. Biomechanical data could

Table 4. Postmortem studies of baseline mice (2 wk of age)

\begin{tabular}{|c|c|c|}
\hline & $\begin{array}{c}+/+ \text { Mice } \\
(n=7)\end{array}$ & $\begin{array}{l}\text { oim/oim Mice } \\
\quad(n=7)\end{array}$ \\
\hline $\begin{array}{l}\text { Average femur length } \\
(\mathrm{mm})\end{array}$ & $10.5 \pm 0.69$ & $8.71 \pm 0.26^{*}$ \\
\hline Average weight (g) & $11.78 \pm 0.85$ & $9.4 \pm 0.5^{*}$ \\
\hline $\begin{array}{l}\text { Femoral endosteal } \\
\text { diameter, AP view } \\
(\mathrm{mm})\end{array}$ & $1.0 \pm 0.07$ & $0.94 \pm 0.07$ \\
\hline $\begin{array}{l}\text { Femoral periosteal } \\
\text { diameter, AP view } \\
(\mathrm{mm})\end{array}$ & $1.21 \pm 0.1$ & $1.16 \pm 0.06$ \\
\hline Cortical thickness (mm) & $0.22 \pm 0.09$ & $0.22 \pm 0.05$ \\
\hline $\begin{array}{l}\text { Femoral endosteal } \\
\text { diameter, ML view } \\
(\mathrm{mm})\end{array}$ & $0.91 \pm 0.11$ & $1.12 \pm 0.14$ \\
\hline $\begin{array}{l}\text { Femoral periosteal } \\
\text { diameter, ML view } \\
(\mathrm{mm})\end{array}$ & $1.12 \pm 0.14$ & $1.12 \pm 0.14$ \\
\hline Moment of inertia & $0.05 \pm 0.03$ & $0.05 \pm 0.02$ \\
\hline
\end{tabular}

* At 2-wk baseline, average femoral length and weight were significantly larger in oim/oim mice than in $+/+$ mice, $p<0.05$. not be obtained on baseline mice due to technical limitations given small size of bones at $2 \mathrm{wk}$ of age and fragility of oim/oim bones.

\section{DISCUSSION}

The results of the current study demonstrate that s.c. administration of ALN to infant mice affected with OI markedly improves metaphyseal bone density and decreases fracture rate without adversely affecting growth. Long bone growth and overall weight gain were maintained with treatment in this study. In humans, ALN, which is given orally, is known to cause gastrointestinal side effects, including gastric and duodenal ulcers (25). Although in mice we have shown comparable weight gain between treated and untreated subjects, the drug may not be tolerated as well when administered orally to nursing infants. The human studies done by Plotkin et al. (16) involved i.v. administration of pamidronate in cycles of three consecutive days every $6-8 \mathrm{wk}$, in which case no adverse side effects of treatment were noted other than an acute phase reaction of short-term fever after the first infusion. Current human studies by Glorieux (26) are focusing on the evaluation of the efficacy of oral drug therapy.

The primary outcome variable examined in the current animal study was fracture incidence. In an earlier study where ALN treatment of oim/oim mice was initiated at $6 \mathrm{wk}$ of age and continued for an 8-wk treatment period, fractures still occurred during the treatment period in the treated mice but to a lesser extent than in nontreated mice (20). In contrast, in the current study, it appears no fractures occurred during the treatment period, inasmuch as the average number of fractures sustained by 14 -wk-old treated mice was equivalent to the average number of fractures seen in 2-wk-old baseline mice. ALN treatment essentially prevented any further fractures from occurring beyond those already present by 2 wk of age. Thus, initiation of bisphosphonate treatment in mice at the early age of 2 wk appears to be even more effective in preventing fractures than when initiated at $6 \mathrm{wk}$.

In addition, in the current study, long bone growth was not affected by ALN treatment in contrast to what was found in the earlier study. This may be attributed to the slightly lower dosage used in the current study $(31 \mu \mathrm{g} / \mathrm{kg} / \mathrm{d})$ compared with the dosages of $73 \mu \mathrm{g} / \mathrm{kg} / \mathrm{d}$ for the first $4 \mathrm{wk}$, followed by 26 $\mu \mathrm{g} / \mathrm{kg} / \mathrm{d}$ for the next $4 \mathrm{wk}$, used previously. In both studies, 


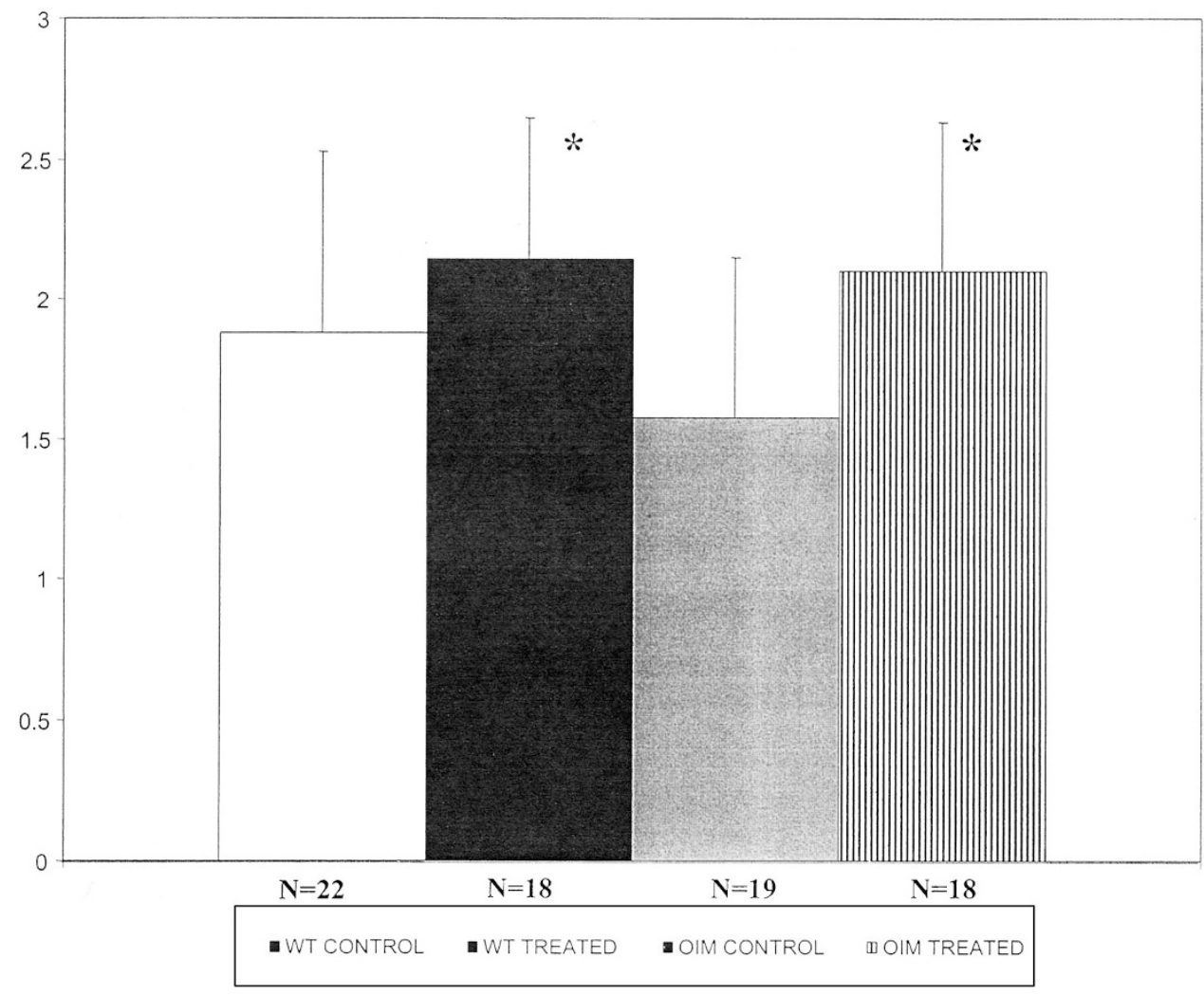

Figure 3. Femoral metaphyseal bone density (intensity units \pm SD) after 12 wk of treatment. Bone density increased significantly with treatment in oim/oim mice $(* p<0.01 v s$ control), making it comparable to that of untreated $+/+$ mice.

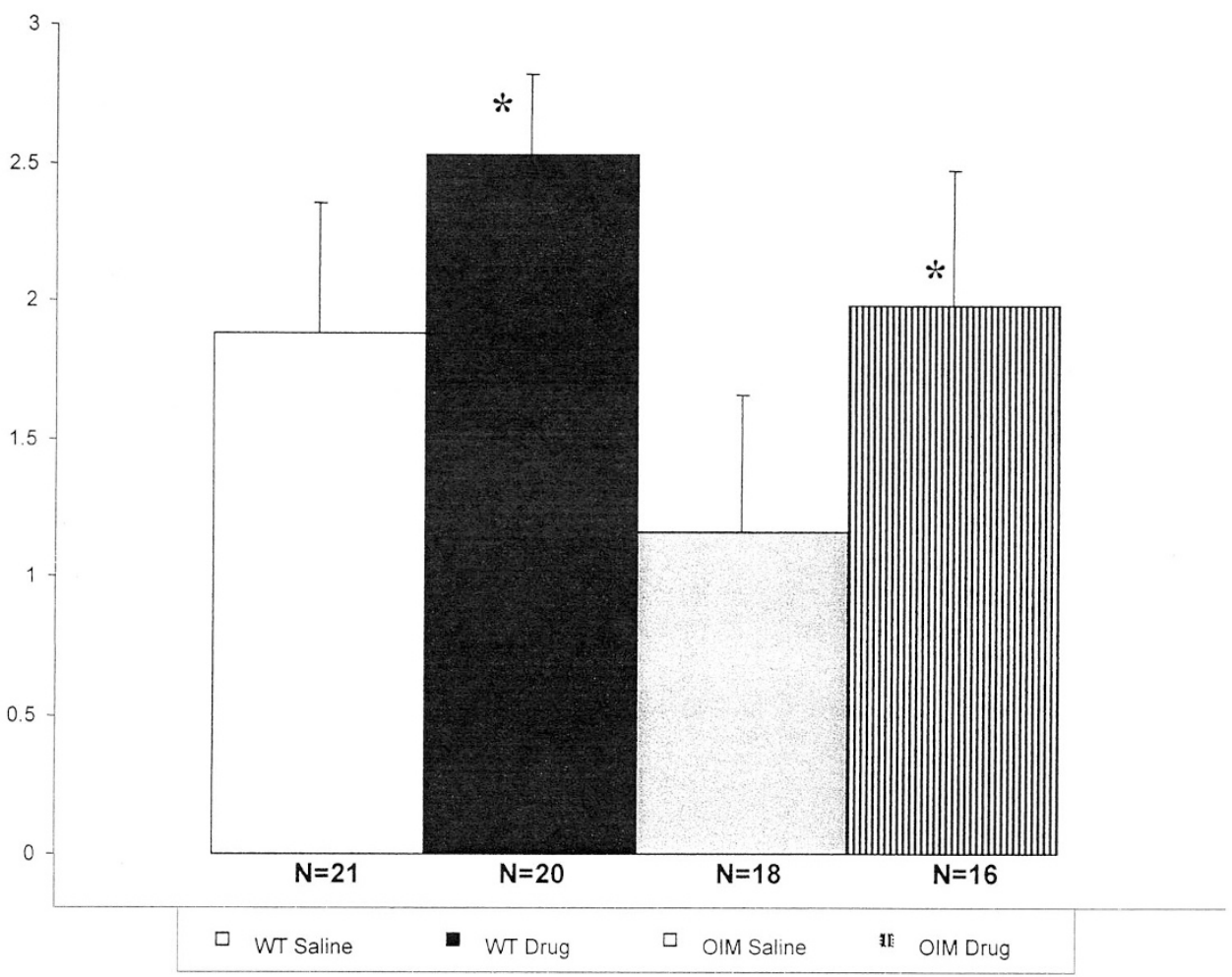

Figure 4. Vertebral density (intensity units \pm SD) after $12 \mathrm{wk}$ of treatment. Density increased significantly with treatment in both the metaphyseal and trabecular regions of the spine in oim/oim mice, making it comparable to that of untreated $+/+$ mice $\left({ }^{*} p<0.01 v s\right.$ control). 

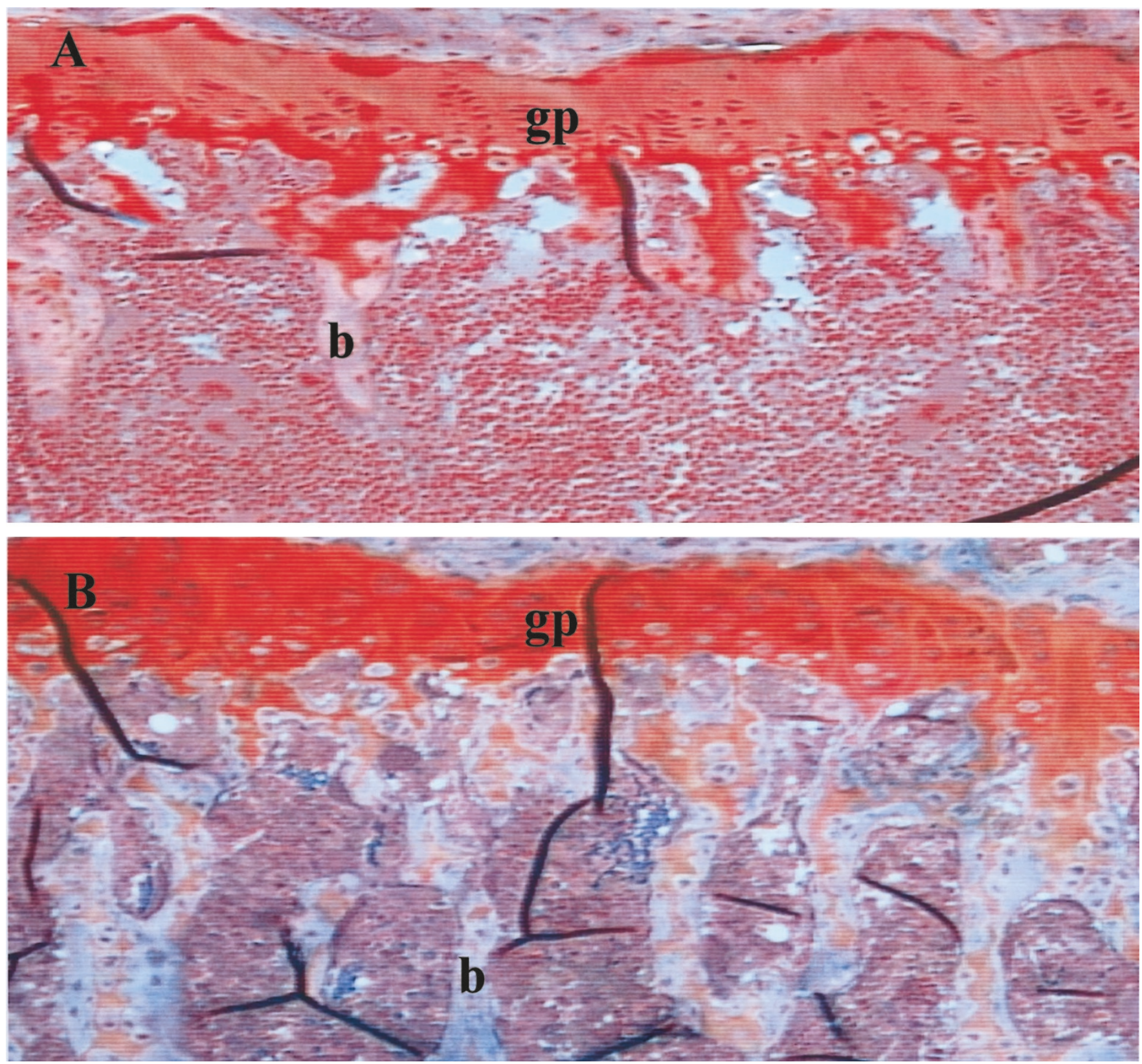

Figure 5. Tibial histology after $12 \mathrm{wk}$ of treatment. Light micrographs of $(A)$ saline-treated and $(B)$ ALN-treated oim/oim tibiae stained with Safranin O (10 $\times$ ). Growth plate $(g p)$ appears red in color and bone $(b)$ appears pink. Growth plate height decreased with treatment and percentage bone under growth plate increased with treatment.

ALN treatment caused an increase in oim/oim femoral metaphyseal density such that it equaled that of the $+/+$ bones. Taken together, these data support the commencement of bisphosphonate treatment of $\mathrm{OI}$ at as early an age as possible. Although we do not know the equivalent age in children, it appears that earlier treatment in mice affected with OI is beneficial. These results also parallel the results seen in recent human studies by Plotkin et al. (16) wherein pamidronate treatment was found to be safe and to increase BMD and decrease fracture rate in severely affected OI patients under 3 y of age.

There are certain limitations to the use of mouse models and, in particular, the oim/oim mouse model of OI. First of all, the genetic mutation in mice is recessive, whereas in most human forms of OI the defect is autosomal dominant. There is, however, a human correlate to the oim/oim mouse model of OI (27). In this variant of OI, the collagen synthesized is a homotrimer of pro $\alpha-1$ chains, and the phenotype is considered severe, similar to the oim/oim mouse model. Thus, the oim/oim mouse is a valid model in which to study the effects of therapy in OI. Nonetheless, one cannot simply translate what is observed in mice directly to humans. For instance, remodeling of bones in mice differs from that in humans in that there is no osteonal network. Therefore, the effect of an antiresorptive drug may be different in humans than in mouse bones. Accordingly, although it appears earlier treatment with ALN in mice with OI is beneficial, we do not know what effects would be seen in human infants nor do we know the equivalent early age in children. 

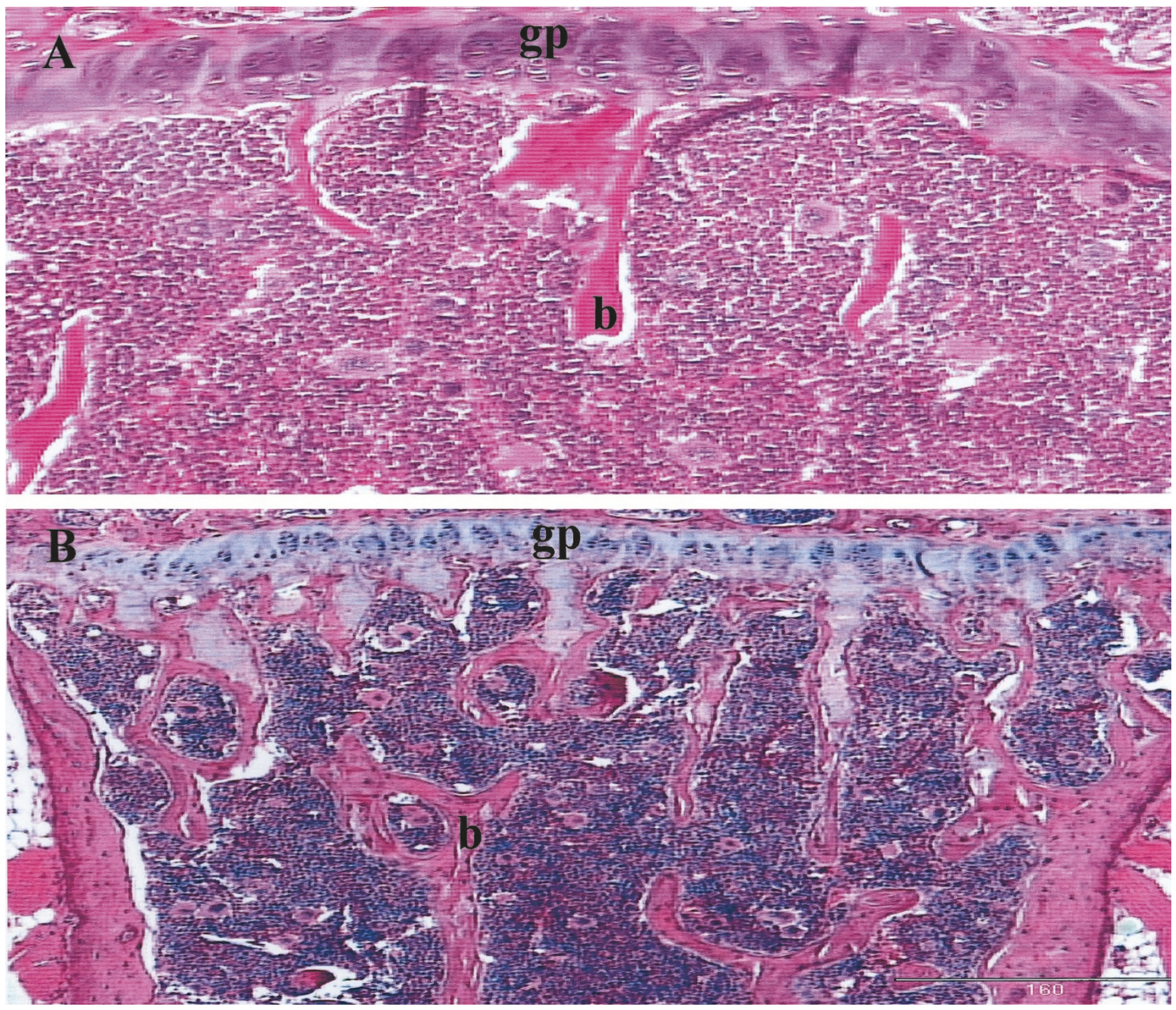

Figure 6. Spine histology after $12 \mathrm{wk}$ of treatment. Light micrographs of hematoxylin and eosin stained spines from $(A)$ saline-treated and $(B)$ ALN-treated oim/oim mice $(10 \times)$. Note improved organization of growth plate $(\mathrm{g} p)$, increased trabecular bone $(b)$, and increased cross-connectivity of trabeculae in ALN-treated mice.

Another critical area of investigation into the effects of bisphosphonates on OI bone is biomechanics. How is bone strength affected by this treatment? In the current study, ALN treatment resulted in increased structural stiffness in oim/oim femurs. Thus, OI bones treated with ALN, although brittle, were stiffer. We believe this is an improvement, based on the decreased incidence of fracture and increased bone density. It is important to note that although increased brittleness was not seen in homozygous oim/oim mice treated with ALN, this does not preclude the possibility of it occurring in humans with mild OI, as was seen in the ALN-treated wild-type mice in the current study. Interestingly, the derived material properties of bone, such as breaking strength and modulus, were not improved and bone geometry was not changed significantly with treatment in the oim/oim mice. One possible explanation for this finding is that three-point bend testing evaluates cortical bone, and in fact there were no changes with treatment in cortical bone density. Thus, it seems the drug may be affecting the metaphyseal region of bone to a greater extent than cortical bone in OI mice. As such, biomechanical evaluation of metaphyseal bone, if feasible, would prove to be more useful. Thus, the means by which structural stiffness increased is still unclear. In other animal studies where rats or rabbits were treated with bisphosphonates, improved mechanical properties were attributed to better bone geometry $(28-30)$.

The precise mechanism by which bisphosphonate treatment reduces the number of fractures is also unknown, although it is known that decreased bisphosphonate-associated remodeling leads to increased BMD (31) or increased bone mineralization (32). In our study, although mechanical and material properties of cortical bone did not increase with treatment, metaphyseal density was increased. This certainly could impact on fracture 
reduction and long bone growth. A similar density increase was also shown in the vertebral bodies. A recent study proposed that antiresorptive agents decrease fracture incidence disproportionally to their effect on bone mass (33), suggesting an additional effect on bone strength unrelated to effects on BMD. An explanation for this phenomenon remains to be seen. Perhaps, as proposed by Plotkin et al. (8), bisphosphonates exert antiapoptotic effects on osteocytic cells and mature osteoblasts. This increase in osteoblast work time may lead to a gradual increase in bone mass, as in trabecular thickness, which in turn may contribute to the antifracture efficacy of these agents.

In the present study in the oim/oim mouse, it does appear that the action of ALN is associated more with an increased bone quantity than with improved tissue quality of bone. Indeed, we have documented an increase in the percentage of bone under the tibial growth plate with treatment. However, there were also improvements in the architecture of the bone. The vertebrae in the ALN-treated oim/oim mice showed an increase in cross-connectivity and width of trabeculae, as well as an increase in the amount of calcified cartilage under the growth plate. In addition to these effects, the tibial growth plates in the oim/oim mice became narrower with ALN treatment, actually approaching the width of the $+/+$ growth plates. These findings suggest a positive effect of ALN on the organization and compactness of the growth plate in the oim/ oim mouse after treatment, which may result in a decreased tendency to fracture. According to Bullough (34), bone biopsy specimens from human patients with the severe or congenital form of OI are characterized by "large areas of osseous tissue that are devoid of an organized trabecular pattern." Furthermore, microscopic analysis of an intact growth plate in OI reveals disorganization of the proliferative and hypertrophic zones (34). Our findings of increased organization of the growth plate in the spine with greater cross-connectivity and width of trabeculae (Fig. 6) also suggest a positive drug effect in the spine, which could lead to increased stability of growth plates and bone. One could speculate that such drug effect may result in a subsequent decrease in the incidence of compression fractures commonly seen in OI, although this was not evaluated in the current study.

Bisphosphonate therapy is now so well validated that their use has extended far beyond osteoporosis to include diseases such as Paget's disease, malignant osteolysis, and fibrous dysplasia (35). Promising preliminary findings, such as those of Glorieux, Plotkin et al. $(15,16)$ warrant the use of bisphosphonates in severe conditions such as OI. Thus, bisphosphonates are rapidly becoming the mainstay of treatment for children with severe OI. One concern is the effect therapy could have on growth in young infants. In studies using older animals, long-term treatment with bisphosphonates did not affect growth, unless very high doses were administered (17). The only human studies to date of bisphosphonate treatment in infants (16) showed no detrimental effect of pamidronate on growth.

A true cure for the disease, which would involve correction of the genetic abnormality, may be decades away. Therefore, any treatment that offers an improvement in quality of life for these severely affected children is welcome. Indeed, treatment during infancy to prevent the painful fractures these infants endure is desirable not only for the immediate comfort to be derived, but also to improve long-term outcome and ambulatory potential. Human studies do indicate earlier treatment is more beneficial (16). But how early can we safely give this antiresorptive drug to infants? Will it interfere with normal bone growth? What are the long-term consequences? Will it be tolerated orally? What is the optimal dose? How long should this treatment be continued? Is it safe to administer to women of childbearing age? Animal studies allow us to examine the biologic plausibility of our hypotheses before attempting human trials. If safety and efficacy can be demonstrated in an infant mouse model of OI, then investigators of human OI may be encouraged to start treatment even earlier.

Ultimately, strengthening bone in OI will require steps to correct the underlying genetic mutations that are responsible for this disorder. Until gene therapy becomes a reality, the best treatment we can offer these patients is bisphosphonates, in an attempt to alter the natural course of this devastating disease (26). We believe that fracture reduction in OI patients will improve their clinical prognosis. As shown by Bembi et al. (13), who used i.v. pamidronate to treat children with OI, "A clear clinical response was shown, with a striking reduction of new fracture episodes and a marked improvement in the quality of the patients' lives." More recently, Zacharin et al. (36) undertook a 2-y study of pamidronate treatment in a cohort of 18 children ages $1.4-14.5 \mathrm{y}$ with OI types III and IV and found sustained cessation of bone pain, improved mobility, and decreased fracture rate in all patients. It stands to reason that fewer fractures translates into decreased pain, decreased bony deformity, decreased need for surgery, and possibly even improved ambulatory potential. The earlier these children receive treatment, the greater their potential to walk and to lead productive lives, free of painful fractures and subsequent surgeries. Hopefully, the promising results demonstrated here will encourage clinical investigators to extend their evaluation of this therapeutic approach to newborn infants with OI, who may stand to benefit the most from clinical intervention at an early age.

Acknowledgments. The authors thank Dalina Stiner, Kwadwo Boachie, and Vivien Zraick for the technical assistance, and the Mechanical Testing Core Facility of The Hospital for Special Surgery. We also thank Merck \& Co., West Point, PA, for supplying the alendronate used in this study.

\section{REFERENCES}

1. Smith R 1995 Osteogenesis imperfecta: the brittle bone syndrome. Curr Orthop 9:28-33

2. Engelbert RHH, Pruijs JEH, Beemer FA, Helders PJM; 1998 Osteogenesis imperfecta in childhood: treatment strategies. Arch Phys Med Rehabil 79:1590-1593

3. Sillence DO, Senn A, Danks DM 1979 Genetic heterogeneity in osteogenesis imperfecta. J Med Genet 16:101-116

4. Glorieux FH, Rauch F, Plotkin H, Ward L, Travers R, Roughley P, Lalic L, Glorieux DF, Fassier F, Bishop NJ 2000 Type V osteogenesis imperfecta: a new form of brittle bone disease. J Bone Miner Res 15:1650-1658

5. Paterson CR, Ogston SA, Henry RM 1996 Life expectancy in osteogenesis imperfecta. BMJ 312:351

6. Castells S 1973 New approaches to treatment of osteogenesis imperfecta. Clin Orthop 93:239-249 
7. Antoniazzi F, Mottes M, Fraschini P, Brunelli PC, Tato L 2000 Osteogenesis imperfecta: practical treatment guidelines. Paediatr Drugs 2:465-488

8. Plotkin LI, Weinstein RS, Parfitt AM, Roberson PK, Manolagas SC, Bellido T 1999 Prevention of osteocyte and osteoblast apoptosis by bisphosphonates and calcitonon. J Clin Invest 104:1363-1374

9. Rogers MJ, Frith JC, Luckman SP, Coxon FP, Benford HL, Monkkonen J, Suriola S, Chilton KM, Russell RGG 1999 Molecular mechanisms of action of bisphosphonates. Bone 24(5):73S-79S

10. Devogelaer JP, Malghem J, Maldague B, Nagant de Deuxchaisnes C 1987 Radiological manifestations of bisphosphonate treatment with APD in a child suffering from osteogenesis imperfecta. Skeletal Radiol 16:360-310

11. Huaux JP, Lokeitek W 1988 Is APD a promising drug in the treatment of severe osteogenesis imperfecta? J Pediatr Orthop 8:71-72

12. Lansmeer-Beker EA, Massa GG, Maaswinkel-Mooy PD, van de Kamp JJP, Papapoulos SE 1997 Treatment of osteogenesis imperfecta with the bisphosphonate olpadronate (dimethylaminohydroxypropylidene bisphosphonate). Eur J Pediatr 156:792-794

13. Bembi B, Parma A, Bottega M, Ceschel S, Zanatta M, Martini C, Ciana G 1997 Intravenous pamidronate treatment in osteogenesis imperfecta. J Pediatr 131:622-625

14. Astrom E, Soderhall S 1998 Beneficial effect of bisphosphonate during five years of treatment of severe osteogenesis imperfecta. Acta Paediatr 87:64-68

15. Glorieux FH, Bishop N, Plotkin H, Chabot G, Lanoue G, Travers R 1998 Cyclic administration of pamidronate in children with severe osteogenesis imperfecta. N Engl J Med 339:946-947

16. Plotkin H, Rauch F, Bishop NJ, Montpetit K, Ruck-Gibis J, Travers R, Glorieux FH 2000 Pamidronate treatment of severe osteogenesis imperfecta in children under 3 years of age. J Clin Endocrinol Metab 85:1846-1850

17. Lepola VT, Hannuniemi R, Kippo K, Lauren L, Jalovaara P, Vaanenen HK 1996 Long-term effects of clodronate on growing rat bone. Bone 18:191-196

18. Ferretti JL, Mondelo N, Capozza RF, Cointry GR, Zanchetta JR, Montuori E 1995 Effect of large doses of olpadronate (dimethyl-pamidronate) on mineral density, cross-sectional architecture, and mechanical properties of rat femurs. Bone 16:285S-293S

19. Chipman SD, Sweet HO, McBride Jr DJ, Davisson MT, Marks Jr SC, Shuldiner AR, Wenstrup RJ, Rowe DW, Shapirt JR 1993 Defective pro alpha 2(I) collagen synthesis in a recessive mutation in mice: a model of human osteogenesis imperfecta. Proc Nat Acad Sci U S A 90:1701-1705

20. Camacho NP, Raggio CL, Doty SB, Root L, Zraick V, Ilg WA, Toledano TR, Boskey AL 2001 A controlled study of the effects of alendronate in a growing mouse model of osteogenesis imperfecta. Calcif Tissue Int 69:94-101

21. Cobb JR 1948 Outline for the study of scoliosis. Instructional course lectures. Am Acad Orthop Surg 5:248-260

22. Turner CH, Burr DB 1993 Basic biomechanical measurements of bone: a tutorial. Bone 14:595-608
23. Shimizu C, Coutts RD, Healey RM, Kubo T, Hirasawa Y, Amiel D 1997 Method of histomorphometric assessment of glycosaminoglycans in articular cartilage. J Orthop Res 15:670-674

24. Zar JH, 1999 Biostatistical Analysis. Prentice Hall, New Jersey, pp 260-261

25. Lanza FL, Hunt RH, Thomson AB, Provenza JM, Blank MA 2000 Endoscopic comparison of esophageal and gastroduodenal effects of risedronate and alendronate in postmenopausal women. Gastroenterology 119:866-869

26. Glorieux FH 2001 The use of bisphosphonates in children with osteogenesis imperfecta. J Pediatr Endocrinol Metab 14(suppl 6):1491-1495

27. Deak SB, van der Rest M, Prockop DJ 1985 Altered helical structure of a homotrimer of alpha 1 (I) chains synthesized by fibroblasts from a variant of osteogenesis imperfecta. Coll Relat Res 5:305-313

28. Pysklywec MW, Moran EL, Bogoch ER 2000 Changes in cross-sectional geometry of the distal femoral metaphysis associated with inflammatory arthritis are reduced by a bisphosphonate (zoledronate). J Orthop Res 18:734-738

29. Ferretti JL, Delgado CJ, Capozza RF, Cointry G, Montuori E, Roldan E, Perez Lloret A, Zanchetta JR 1993 Protective effects of disodium etidronate and pamidronate against the biomechanical repercussion of betamethasone-induced osteopenia in growing rat femurs. Bone Miner 20:265-276

30. Osterman T, Lauren L, Kuurtamo P, Hannuniemi R, Isaksson P, Kippo K, Peng Z, Vaananen HK, Sellman R 1998 The effect of orally administered clodronate on bone mineral density and bone geometry in ovariectomized rats. J Pharmacol Exp Ther 284:312-316

31. Murphy MG, Weiss S, McClung M, Schnitzer T, Cerchio K, Connor J, Krupa D, Gertz BJ; MK-677/Alendronate Study Group 2001 Effect of alendronate and MK-677 (a growth hormone secretagogue), individually and in combination, on markers of bone turnover and bone mineral density in postmenopausal osteoporotic women. J Clin Endocrinol Metab 86:1116-1125

32. Boivin GY, Chavassieux PM, Santora AC, Yates J, Meunier PJ 2000 Alendronate increases bone strength by increasing the mean degree of mineralization of bone tissue in osteoporotic women. Bone 27:687-694

33. Cummings SR, Black DM, Vogt TM 1996 Changes in BMD substantially underestimate the anti-fracture effects of alendronate and other antiresorptive drugs. J Bone Miner Res 11(suppl):S102(abstr)

34. Bullough PG 1992 Atlas of Orthopaedic Pathology with Clinical and Radiologic Correlations. Gower Medical Publishing, Philadelphia, pp 5.8-5.12

35. Orcel P, Beaudreuil J 2002 Bisphosphonates in bone diseases other than osteoporosis. Joint Bone Spine 69:19-27

36. Zacharin M, Bateman J 2002 Pamidronate treatment of osteogenesis imperfectalack of correlation between clinical severity, age at onset of treatment, predicted collagen mutation and treatment response. J Pediatr Endocrinol Metab 15:163174 